\title{
O SAGRADO, A DUALIDADE HUMANA E A NATUREZA SOCIAL DA RELIGIÃO: APRESENTAÇÃO ÀS TRADUÇÕES
}

Raquel Weiss ${ }^{1}$

Neste ano em que se celebra o centenário de publicação de As Formas Elementares da Vida Religiosa, o presente fascículo traz para o leitor a tradução de dois textos que são da maior importância para a compreensão dessa obra. E por quê? Qual a relação desses textos com o livro de 1912? Porque em ambos os textos temos uma visão privilegiada sobre o que o próprio autor do livro considerava como sendo aquilo que havia de mais essencial em $A s$ Formas Elementares e que considerava não ter sido compreendido por seus intérpretes.

Portanto, antes de apresentar cada um dos textos, proponho fazer algumas breves considerações sobre o momento em que foram concebidos. Após a publicação do referido livro, Durkheim engajou-se seriamente nas atividades de divulgação da recente obra, não tanto para torná-la conhecida, - àquela altura o autor já gozava de amplo prestígio nos meios intelectuais, o que garantira a rápida divulgação de seu novo livro, um evento particularmente importante, considerando-se que sua última grande obra publicada havia sido Le Suicide, em 1897. Seu objetivo fundamental era o de aclarar seu sentido, afinal, parecia-lhe causar alguma frustração o fato de que seu argumento mais essencial havia escapado até a seus melhores e mais dedicados leitores, como Gustave Belot, o primeiro a redigir uma resenha sobre o livro (Belot, 1913).

Por parte dos "homens de fé" Durkheim já não gozava de grade apreço, especialmente em virtude de seu comprometimento com a instituição

${ }^{1}$ Professora adjunta do departamento de Sociologia da UFRGS, pesquisadora do NER e diretora do Centro Brasileiro de Estudos Durkheimianos. Contato: weiss.raquel@gmail.com 
de uma educação moral laica e de seu antimonarquismo. Como se não bastasse querer ensinar uma moral sem Deus, ainda inventou de publicar um livro que não apenas tinha o grave inconveniente de querer explicar sociologicamente a religião, afirmando ser ela um fenômeno essencialmente social, como ainda cometeu a grosseria de comparar as religióes altamente intelectualizadas e espiritualizadas, como o Protestantismo e o Catolicismo, às religiōes tribais ${ }^{2}$.

Todavia, até mesmo do lado dos libres penseurs, o seu mais recente trabalho parecia ter causado incômodo, provavelmente em virtude de sua insistência em querer mostrar aquilo que havia de verdadeiro em todas as religiōes, por afirmar que a religião não é uma mera "alucinação coletiva". Ou seja, num contexto de um laicismo extremamente combativo, sua explicação para o fenômeno religioso parecia ainda ser demasiado condescendente para com as religióes, mesmo que ele fosse extremamente crítico em relação às Igrejas, especialmente à Igreja católica, chegando mesmo a afirmar que “[...] do ponto de vista sociológico, a Igreja é um monstro" (1905, p. 369)3

Tendo desagradado aos mais radicais de ambos os lados, em vez de simplesmente combater de frente cada uma das críticas que lhe foram dirigidas, ele concentrou os esforços em mostrar que eles simplesmente não haviam compreendido aquilo que, na realidade, era o mais importante de tudo aquilo que ele escrevera. Assim, talvez uma das melhores maneiras de se ler As Formas Elementares seja tomar essas ponderações posteriores como chaves de leituras. Aliás, o texto traduzido a seguir consiste na transcrição da primeira discussão pública a respeito de seu livro, no qual teve ocasião de expô-lo junto aos membros da Société Française de Philosophie, que em seguida o debateram. Nesse momento ele formula de maneira bastante interessante a natureza de sua inquietação e mostra qual é, então, esse

\footnotetext{
2 Para uma análise abrangente da reação dos católicos e protestantes à obra durkheimiana, não se pode deixar de ler o recente artigo publicado por William Pickering (2008), que preencheu uma importante lacuna no campo das pesquisas que visam a reconstruir o meio intelectual de Durkheim.

${ }^{3}$ (Durkheim, 1905, p. 369)
} 
elemento mais fundamental, sugerindo, inclusive, o porquê de não ter sido bem compreendido:

Não poderia pensar em resumir aqui o livro que publiquei recentemente. Mas gostaria de colocar em relevo a razão de ser fundamental da religião, que permite preparar melhor os espíritos a aceitar a explicação que eu propus a seu respeito. Essa razão de ser se vincula a uma das características mais essenciais da religião, mas que não é imediatamente perceptível, precisamente porque é essencial. Ela não é formulada logo no início do livro. Ela aparece apenas progressivamente, na medida em que o estudo avança, e é especialmente na conclusão que ela ganha destaque. Essa característica é aquilo a que poderíamos chamar de virtude dinamogênica de toda espécie de religião ${ }^{4}$. (Durkheim, 2012a)

Na realidade, esse trecho é absolutamente central para a compreensão do elemento estruturante da vida religiosa e, inclusive, está na base de sua concepção de sagrado, qual seja o fato de que a vida religiosa, que é uma vida coletiva, tem uma propriedade "dinamogênica", isto é, ela faz aumentar o fluxo de energia, ela faz com que os indivíduos se sintam mais fortes na medida em que se alimentam dessa força. Portanto, mais do que ordenar o mundo, mais do que dar sentido ao mundo e à própria vida, como no caso da concepção weberiana; o elemento primordial da religião é fazer o homem agir, na medida em que o torna mais forte, mais capaz, mais cheio de energia vital'5.

E é essa mesma característica que Durkheim continua a defender no segundo texto aqui traduzido, que consiste em uma carta dirigida à mesma Société de Philosophie. Seu objetivo foi o de responder às intervenções feitas por Lucien Laberthonnière, um teólogo progressista, que havia criticado o livro de Durkheim com base no argumento de que as religiōes "primitivas" não são exatamente religióes, logo, todo o propósito do livro, de tentar

${ }^{4}$ (Durkheim, 1913, 17[1913b]) Tradução de O Problema Religioso e a Dualidade da natureza humana.

${ }^{5}$ Para mais informações a respeito da ideia de dinamogenia, veja-se Miller (2005) e Weiss (2011). 
encontrar os elementos mais fundamentais da vida religiosa a partir de um estudo das religiōes ditas "primitivas", seria falacioso.

O leitor atento verá que tanto no primeiro, a exposição oral seguida de um debate, quanto no segundo, que consiste em uma carta, há um elemento que perpassa toda a discussão, que é a tese da qual Durkheim não abre mão um só instante: é a tese de que a religião é um fenômeno eminentemente social, que existe porque existe a vida coletiva e que existe para que essa vida coletiva continue a existir. $\mathrm{Ou}$, em suas palavras, "[...] não vejo como se pode viver para a sociedade se não se vive por meio dela" (Durkheim, 2012b, p. 66)

É precisamente essa "natureza social" da religião, enquanto coisa coletiva que produz efervescência, que está na base da defesa de sua concepção sobre o caráter dual da natureza, e que consiste em uma tentativa de dar uma resposta sociológica a um dos temas mais centrais da filosofia e da teologia, qual seja, a dualidade entre "corpo" e "alma".

Segundo o autor, o ser humano, em todos os tempos, sempre teve o vivo sentimento dessa dualidade. Por toda parte ele se concebeu como sendo formado por dois seres radicalmente heterogêneos: o corpo, de um lado, a alma, de outro. Portanto, ele nega as teorias do homo duplex já estabelecidas, mas tenta explicar qual é a realidade que funda essa ideia, do mesmo modo que tentou mostrar aquilo que havia de verdadeiro nas religiōes e em suas concepçōes sobre as divindades. Não é muito difícil intuir que a sua solução para essa questão consiste em afirmar que o corpo corresponde ao nosso "ser individual", enquanto a alma é aquilo que constitui o nosso "ser social".

O ser individual e o ser social são dois sistemas de "estados de consciência" (Durkheim, 1968, p. 602), que diferem em termos de suas origens e de suas propriedades, e é por isso mesmo que se contradizem e se negam mutuamente. Resumidamente, o que veremos é que a dualidade da natureza

\footnotetext{
${ }^{6}$ Essa discussão sobre a dualidade entre corpo e alma aparece de forma difusa em As Formas Elementares, e é reelaborada no artigo Le Dualisme de la Nature Humaine et ses Conditions Sociales (Durkheim, 1914a), no qual a discussão não aparece tão vinculada à religião, como no artigo que está sendo analisado.
} 
humana é uma expressão da própria dualidade que existe entre o sagrado e o profano, é apenas um caso particular dessa divisão entre as coisas que está presente em todas as religiōes.

Desse modo, somos levados a retornar à ideia de dinamogenia, que está na base da formação do sentimento de sagrado, mas olhando-a agora do ponto de vista do indivíduo. Grosso modo, o sentimento do sagrado é resultante da percepção que temos dessa "operação psíquica" que é chamada de "fusão", a comunhão das consciências individuais em uma consciência comum. Trata-se de um fato ao mesmo tempo fisiológico, psíquico e sociológico, que tem impacto sobre o corpo, sobre os sentimentos, sobre as ideias:

Quando esses ideais movem nossa vontade, nós nos sentimos conduzidos, dirigidos, arrebatados por energias singulares que, evidentemente, não vêm de nós, mas se impõem a nós, e em relação às quais temos sentimentos de respeito, de reverência, mas as quais também reconhecemos como causa do conforto que recebemos; porque elas não podem se chegar até nós sem aumentar nosso tônus vital. E essas virtudes sui generis não se devem a nenhum tipo de ação misteriosa, são simplesmente os efeitos dessa operação psíquica, cientificamente analisável, mas singularmente criativa e fecunda, a que chamamos de fusão, de comunhão de uma pluralidade de consciências individuais em uma consciência comum (Durkheim, 1914b, p. 215)

Temos, assim, que a consciência dessa vida psíquica excepcional é o primeiro elemento a fornecer a percepção dessa natureza dupla, pois faz com que o indivíduo sinta nele forças que são diferentes daquelas que ele próprio possui. Mas isso não é suficiente. Essas forças não chegam até ele apenas nos momentos de efervescência, elas estão nele de forma permanente, porque estão encarnadas em certas representaçóes que constituem a sua vida psíquica, que são as próprias representações coletivas, que dizem respeito tanto à sua vida intelectual quanto moral. É desse modo que os ideais passam a ser constitutivos das representaçôes internas que orientam o pensamento e a volição dos indivíduos.

Esse mecanismo é aqui apresentado como aquele mediante o qual o ser social penetra no ser individual, fazendo sua morada na pluralidade dos 
indivíduos que passam a representar esse ideal, cada qual à sua maneira. Uma vez enraizado, ele deixa de ser uma representação viva e pulsante e se converte no que poderíamos chamar de um "ideal mnêmico", isto é, fixado na memória, mas como toda lembrança, parcialmente destituído da potência da qual era investido no momento de sua gênese. Mas, veja-se bem, apenas parcialmente.

Esse ideal, que é também um tipo de representação, é sentido pelo indivíduo como sendo diferente de suas demais representações individuais, e, ao mesmo tempo, o tipo de reação psíquica que ele provoca não é do mesmo gênero que aquelas diretamente vinculadas à sua vida individual, porque nela existe algo que parece ser de outra natureza, que o vincula a um mundo estranho, que não coincide com aquele de sua própria existência, de seus próprios sentimentos. Essas forças são despertadas e reavivadas especialmente nas celebraçóes coletivas, que fazem com que os indivíduos voltem a ter contato direto com a verdadeira origem desse sentimento que ele experiencia em relação a essas representações muito especiais, inclusive aquelas gestadas em momentos de efervescência dos quais ele não chegou a tomar parte.

O que é importante levar em consideração aqui é que os ideais são um "produto da vida em grupo", e é nesse sentido que são sociais, pois as grandes concepções são tiradas do próprio seio da sociedade nos momentos de efervescência. Passado esse momento excepcional, a força do ideal não se dissolve plenamente, justamente porque a vida coletiva não deixa de existir, embora se mantenha em intensidade menor. A seguir, vemos como esses ideais coletivos são assimilados pela consciência individual, misturando-se com nossas próprias representaçóes, engendrando um processo que não apenas garante a sua perpetuação, mas que também cria a percepção da dualidade de nosso ser:

Mesmo sendo nossas, essas representações falam a nós com outro tom, com uma inflexão diferente que o restante de nossos estados de consciência: elas nos ordenam, impõem-nos respeito, não nos sentimos em pé de igualdade 
em relação a ela. Assim percebemos que elas representam em nós algo que nos é superior. (Ibidem, p. 214).

Podemos ver nesse trecho um resumo de sua explicação sobre a dualidade da natureza humana. Ela é real e exprime essa coexistência entre o nosso ser individual, que concerne a nosso organismo biológico, a nossa relação com o mundo, a nossas experiências pessoais e o ser coletivo, que vive parcialmente em nós, mas tem outra origem. E não podemos existir sem que sejamos, a um só tempo, esses dois seres que são, na realidade, dois "estados de consciência". A existência desse ser social como parte constitutiva da natureza humana é o que garante que o indivíduo esteja sempre vinculado à coletividade e a seus ideais, porque ele não pode negá-los sem ao mesmo tempo negar parte de si mesmo.

É por isso, por exemplo, que tomar consciência da origem social de nossos valores não é suficiente para cessar a influência que eles exercem sobre nós, fazendo com que o cumprimento da regra moral apareça como algo tão fundamental, cuja violação, por mais que saibamos, não é um decreto divino, sempre provoca a sensação de violação da própria consciência, afinal o ideal que a anima é parte de nossa própria consciência. Mas dizer dessas representações que elas são de origem exógena ainda não é suficiente para esgotar a questão a respeito de sua heterogeneidade e mesmo da oposição em relação às representações individuais. Elas diferem destas porque possuem um caráter impessoal.

Assim, as representações individuais são pessoais, dizem respeito ao mundo tal como é percebido pela nossa sensibilidade e seus imperativos práticos dizem sempre respeito aos nossos interesses pessoais, enquanto as representaçóes coletivas orientam nossa conduta na direção de fins sociais e intermedeiam nossa relação com o mundo a partir de conceitos partilhados intersubjetivamente. Aliás, é o próprio fato de que compartilhamos esses ideais o que garante a possibilidade da vida em comum, porque é isso que permite a comunicação, não apenas pela linguagem, mas também porque existe uma forma partilhada de pensar e de sentir, que não é idêntica, evidentemente, mas que possui elementos comuns. 
Se concedermos razão aos argumentos de Durkheim, aceitaremos que a natureza humana é realmente dual, que isso não é algo como um delírio religioso ou uma elucubração metafísica. A consequência disso é que somos naturalmente divididos contra nós mesmos. Trata-se, portanto, de um fator de perpétua inquietude, pois esse "dilaceramento" que exprime a coexistência do sagrado e do profano em seu ser é o que faz com que o homem jamais experimente qualquer forma de alegria pura, porque a ela sempre se mistura alguma dor, porque não podemos satisfazer simultaneamente esses dois seres que existem em nós (Durkheim, 2012). Finalmente, é do fato de que as representações coletivas são constitutivas da nossa própria natureza que é possível que exista a sociedade não apenas enquanto um agregado físico de corpos, mas como um conjunto de consciências que conseguem interagir, na medida em que compartilham certas representaçóes.

Portanto, o que vemos nesses dois textos cuja tradução é agora apresentada ao leitor brasileiro, é o núcleo duro da concepção durkheimiana de religião. Ao considerá-la um fenômeno eminentemente social, Durkheim faz do estudo do fenômeno religioso a chave para compreender os aspectos mais essenciais da vida humana, inclusive sua inelutável dualidade.

\section{REFERENNCIAS}

BELOT, Gustave. Une Nouvelle Théorie de la Religion. Revue Philosophique v. 75, p. 329-379, 1913.

DURKHEIM, Émile. Sur la Séparation des Églises et de l'état [contribuição à discussão]. Libres Entretiens de L'Union pour la Vérité v. 1, p. 369-371, 496-500. 1905.

. Le Problème Religieux et la Dualité de la Nature Humaine. Bulletin de la Sociéte Française de Philosophie. v. 13, p. 63-100, 1913.

. Le Dualisme de la Nature Humaine et ses Conditions Sociales.

Scientia. v. 15, p. 206-221, 1914. 
. Les Formes Elementaires de la Vie Religieuse. Paris: Presses Universitaires de France, 1968.

. O Problema Religioso e a Dualidade da Natureza Humana, 2012a.

. Considerações a respeito dos cultos primitivos e a função do sagrado. In: Debates do NER, n. 22, p. 63-66, 2012.

MILLER, William Watts. Dynamogénique and Élementaire. Durkheim Studies v. 11, p. 18-32, 2005.

PICKERING, W. S. F. The Response of Catholic and Protestant Thinkers to the Work of Émile Durkheim - With Special Reference to Les Formes Elementaires. Durkheim Studies. v. 14, p. 59-93, 2008.

WEISS, Raquel. Émile Durkheim e a Fundamentação Social da Moralidade. Doutorado. São Paulo. Universidade de São Paulo, 2011. 